\title{
NEW BUTYROLACTONE FROM A MARINE-DERIVED FUNGUS ASPERGILLUS SP
}

\section{AURELIO SAN-MARTÍN ${ }^{\prime *}$, JUANA ROVIROSA ${ }^{1}$, INMACULADA VACA ${ }^{1}$, KAREN VERGARA ${ }^{1}$, LAURA ACEVEDO ${ }^{2}$, DOLORES VIÑA ${ }^{2}$, FRANCISCO ORALLO ${ }^{\dagger 2}$ AND MARÍA CRISTINA CHAMY}

\author{
${ }^{1}$ Departamento de Química, Facultad de Ciencias, Universidad de Chile, Las Palmeras 3425, Ññoa, Santiago, Chile. \\ ${ }^{2}$ Departamento de Farmacología, Facultad de Farmacia e Instituto de Farmacia Industrial, Universidad de Santiago de Compostela, \\ Campus Universitario Sur, 15782, Santiago de Compostela, España. \\ ${ }^{3}$ Departamento de Química, Facultad de Ecología y Recursos Naturales, Sede Viña del Mar, Universidad Andrés Bello, Avda Los Fresnos 52 , \\ Viña del Mar, Chile \\ (Received: October 6, 2010 - Accepted: March 28, 2011)
}

\begin{abstract}
Four compounds that belong to two structure types, namely dibenzylbutyrolactone and sesterterpenoids, were obtained from the extract of the strain Aspergillus sp. (2P-22), isolated from a marine sponge, Cliona chilensis. Among them, compound $\mathbf{1}$ was identified as new, namely butylrolactone-VI. The structures of these compounds were characterized on the basis of spectroscopic data. Biological activities of these fungal metabolites, are described.
\end{abstract}

Keywords: marine-derived fungus, Aspergillus sp. (2P-22); dibenzylbutyrolactone; sesterterpenoids.

\section{INTRODUCTION}

In the search for novel and bioactive molecules, terrestrial fungi have yielded many biologically active compounds. More recently, marine microorganisms have gained attention as important sources of chemically interesting and biologically active secondary metabolites, due to the diversity in chemical structures and biological activities ${ }^{1,2}$. However, compared with other marine organisms, relatively few investigations of the secondary metabolites from marine fungi have been reported ${ }^{3}$. Fungi isolated from various organisms in the marine environment, e.g., from mangroves ${ }^{4}$, algae $^{5}$, mollusks $^{6}$ and particularly sponges ${ }^{7}$, have been examined for their secondary metabolite content.

As part of our research on marine fungi, we report here the results regarding the secondary metabolite chemistry of 2P-22 strain, Aspergillus sp., isolated from the marine sponge Cliona chilensis collected in Los Molles, IV Region, Chile. This study led to the isolation of a new compound $\mathbf{1}$, together with three known compounds previously isolated from other fungal sources ${ }^{8-11}$ (Figure 1). The new compound is structurally related to the known butyrolactone I isolated from Aspergillus terreus. ${ }^{12} \mathrm{We}$ described the isolation, structure elucidation, and biological activities of these fungal metabolites.
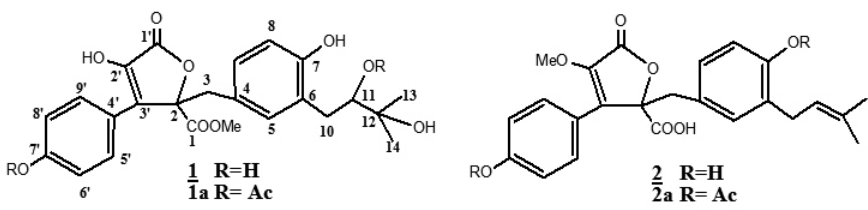

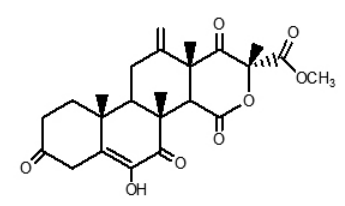

$\underline{3}$

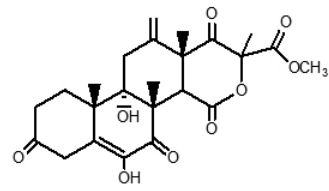

$\underline{4}$

\section{EXPERIMENTAL}

\section{General experimental procedures.}

${ }^{1} \mathrm{H}$ and ${ }^{13} \mathrm{C}-\mathrm{NMR}$ spectra were recorded on a Bruker AMX2-400 spectrometer, operating at 400.13 for ${ }^{1} \mathrm{H}$ and $100.6 \mathrm{MHz}$ for ${ }^{13} \mathrm{C}$. Chemical shifts are reported in ppm $(\delta)$ and coupling constant $(J)$ are given in Hz. The spectra were obtained in $\mathrm{CDCl}_{3}$ solutions and are referred to the residual peaks of $\mathrm{CHCl}_{3}$ at $\delta 7.26 \mathrm{ppm}$ and $77.0 \mathrm{ppm}$ for ${ }^{1} \mathrm{H}$ and ${ }^{13} \mathrm{C}$ respectively. Mass spectra were taken at $70 \mathrm{eV}$ (probe) in a Micromass Autospec spectrometer. Semipreparative HPLC was carried out with a Beckman System Gold 125P. Dry column chromatography was performed on Merck (0.02-0.063 mm) silica gel.

\section{Fungal Material.}

The fungi isolate was recovered from the surface of the sponge Cliona chilensis collected in the Pacific Sea, Los Molles (IV Región, Chile), during September 2007. A sample of this strain was deposited in the Laboratory of Marine Natural Products of the Universidad de Chile coded as 2P-22 and kept in agar slants with potato dextrose agar (PDA) as culture medium. The strain was seeded in Petri dishes with PDA culture medium in seawater and incubated for 7 days at $28^{\circ} \mathrm{C}$. Then, a solution of Tween $80(0.05 \%)$ in sterile distilled water was used to obtain a spore suspension. This suspension was poured into an Erlenmeyer flask containing $150 \mathrm{~mL}$ of Czapeck medium $(5 \mathrm{~g}$ of yeast extract, $30 \mathrm{~g}$ of sucrose, $2 \mathrm{~g}$ of $\mathrm{KNO}_{3}, 0.5 \mathrm{~g}$ of $\mathrm{KCl}, 0.01 \mathrm{~g}$ of $\mathrm{FeSO}_{4}$ $\mathrm{x} 7 \mathrm{H}_{2} \mathrm{O}, 0.5 \mathrm{~g}$ of $\mathrm{MgSO}_{4} \times 7 \mathrm{H}_{2} \mathrm{O}, 1 \mathrm{~g}$ of $\mathrm{KH}_{2} \mathrm{PO}_{4}, 1 \mathrm{~L}$ of seawater) and cultured at $27^{\circ} \mathrm{C}$ with $230 \mathrm{rpm}$ for $48 \mathrm{~h}$ to prepared a stock inoculum. The large-scale fermentation was performed in Erlenmayer flask $(10 \times 1 \mathrm{~L}$ each) containing 200 $\mathrm{mL}$ of Czapeck medium and $20 \mathrm{~mL}$ of inoculum. The cultures were incubated on an orbital shaker $(230 \mathrm{rpm})$ at $27^{\circ} \mathrm{C}$ for 25 days.

The mycelium was removed from the culture broth by filtration. Both the broth and the mycelium were studied. First, the broth (10 L) was extracted with EtOAc, $(3 \times 1.5 \mathrm{~L})$. The resulting organic extract was dried under reduced pressure to obtain a brown solid $(0.5 \mathrm{~g})$, which was fractionated by column chromatography on silica gel using stepwise gradient elution from $70 \%$ hexane in ethyl acetate, to $100 \%$ ethyl acetate, to $100 \%$ methanol. The volume eluted in each step was $0.5 \mathrm{~L}$, and 10 fractions were obtained and evaporated to dryness. Moreover, the dried mycelium $(12 \mathrm{~g})$ was first extracted with $\mathrm{CH}_{2} \mathrm{Cl}_{2}$ $(3 \times 1 \mathrm{~L})$ to give $1 \mathrm{~g}$ of dichloromethane extract and then with $\mathrm{CH}_{3} \mathrm{OH}(3 \times 1 \mathrm{~L})$ to obtain $11 \mathrm{~g}$ of methanol extract. Purification of the resulting fractions of the organic culture broth allowed us to obtain the pure compounds $\underline{\mathbf{1}} \underline{\mathbf{4}}$ as follows: the methanol extract was fractionated on a Sephadex LH-20 column using a 6:2:1 $n$-hexane $/ \mathrm{CH}_{2} \mathrm{Cl}_{2} / \mathrm{MeOH}$ solvent system to obtain 20 fractions. Fraction $10(100 \mathrm{mg})$ was further separated using silica gel (200-300 mesh) CC with 
a gradient solvent system from $50 \%$ petroleum ether/EtOAc to $100 \%$ EtOAc to yield 27 fractions ( $50 \mathrm{~mL}$ for each fraction). The fractions were monitored by TLC. Further purifications were made by chromatography on silica gel isolating compounds $\mathbf{1}$ and $\underline{\mathbf{2}}$. From the purification by chromatography on silica gel using as mobile phase hexane/EtOAc (8:3), fractions 15 and 18 contained compounds $\underline{3}$ and $\underline{4}$ respectively. Compounds $\underline{\mathbf{2}}$ - $\underline{\mathbf{4}}$ were identified by comparison of their spectroscopic properties with those reported ${ }^{8-13}$.

Compound (1): ${ }^{1} \mathrm{H}-\mathrm{NMR}(\boldsymbol{\delta}, 400 \mathrm{MHz}):, 7.59(2 \mathrm{H}, \mathrm{d}, \mathrm{J}=8.8 \mathrm{~Hz}, \mathrm{H}-5$ and $\left.\mathrm{H}_{-} 9^{\prime}\right), 6.90\left(2 \mathrm{H}, \mathrm{d}, \mathrm{J}=8.8 \mathrm{~Hz}, \mathrm{H}-6^{\prime}\right.$ and $\left.\mathrm{H}-8^{\prime}\right), 6.58(1 \mathrm{H}, \mathrm{brs}, \mathrm{H}-5), 6.55$ $(1 \mathrm{H}, \mathrm{d}, \mathrm{J}=8.3 \mathrm{~Hz}, \mathrm{H}-8), 6.52(1 \mathrm{H}, \mathrm{dd}, \mathrm{J}=2.0,8.3 \mathrm{~Hz}, \mathrm{H}-9), 4.94(1 \mathrm{H}, \mathrm{t}, \mathrm{J}=4.9$ $\mathrm{Hz}, \mathrm{H}-11), 3.78\left(3 \mathrm{H}, \mathrm{s}, \mathrm{OCH}_{3}\right), 3.76(1 \mathrm{H}, \mathrm{t}, \mathrm{J}=4.9 \mathrm{~Hz}, \mathrm{H}-11), 3.53(1 \mathrm{H}, \mathrm{d}$, $\mathrm{J}=14.7 \mathrm{~Hz}, \mathrm{H}-3 \mathrm{a}), 3.45(1 \mathrm{H}, \mathrm{d}, \mathrm{J}=14.7 \mathrm{~Hz}, \mathrm{H}-3 \mathrm{e}), 2.88(1 \mathrm{H}, \mathrm{dd}, \mathrm{J}=4.6,17.0$ $\mathrm{Hz}, \mathrm{H}-10 \mathrm{a}), 2.62(1 \mathrm{H}, \mathrm{dd}, \mathrm{J}=5.1,17.0 \mathrm{~Hz}, \mathrm{H}-10 \mathrm{e}), 1.31(3 \mathrm{H}, \mathrm{s}, \mathrm{Me}-13), 1.24$ (3H, s, Me 14). ${ }^{13} \mathrm{C}-\mathrm{NMR}: 169.7$ (C-1), 85.9 (C-2), 38.7 (C-3), 128.0 (C-4), 132.1 (C-5), 118.2 (C-6), 151.9 (C-7), 116.7 (C-8), 129.6 (C-9), 31.0 (C-10), 69.6 (C-11), 77.2 (C-12), 24.6 ( C-13), 22.4 (C-14), 169.2 (C-1'), 137.4 (C-2'), 124.7 (C-3'), 128.0 (C-4'), 129.5 (C-5' and C-9'), 116.0 (C-6' and C-8'), 156.6 (C-7'). EIMS m/z (rel. int.): 458[M] (1), 440 (3), 422 (2), 405 (15), 391 (4), 319 (5), 237 (7), 217 (12), 216 (63), 202 (8), 154 (6), 149 (10), 122 (9), 104 (13), 99 (36), 94 (57), 93 (5);

Compound (1a) $)^{~}{ }^{H} \mathrm{H}-\mathrm{NMR}(\boldsymbol{\delta}, 400 \mathrm{MHz}): 7.72(2 \mathrm{H}, \mathrm{d}, \mathrm{J}=8.8 \mathrm{~Hz}, \mathrm{H}-5$ ' and H-9'), $7.20\left(2 \mathrm{H}, \mathrm{d}, \mathrm{J}=8.8 \mathrm{~Hz}, \mathrm{H}-6^{\prime}\right.$ and $\left.\mathrm{H}-8^{\prime}\right), 6.62(1 \mathrm{H}, \mathrm{dd}, \mathrm{J}=1.5,8.5 \mathrm{~Hz}$ $\mathrm{H}-9), 6.58(1 \mathrm{H}, \mathrm{d}, \mathrm{J}=8.5 \mathrm{~Hz}, \mathrm{H}-8), 6.48(1 \mathrm{H}, \mathrm{brs}, \mathrm{H}-5), 4.94(1 \mathrm{H}, \mathrm{t}, \mathrm{J}=5.2 \mathrm{~Hz}$, $\mathrm{H}-11), 3.78(3 \mathrm{H}, \mathrm{OCH}), 3.56(1 \mathrm{H}, \mathrm{d}, \mathrm{J}=14.8 \mathrm{~Hz}, \mathrm{H}-3 \mathrm{a}), 3.45(1 \mathrm{H}, \mathrm{d}, \mathrm{J}=14.8$ $\mathrm{Hz}, \mathrm{H}-3 \mathrm{e}), 2.90(1 \mathrm{H}, \mathrm{dd}, \mathrm{J}=5.1,17.3 \mathrm{~Hz}, \mathrm{H}-10 \mathrm{a}), 2.60(1 \mathrm{H}, \mathrm{dd}, \mathrm{J}=5.3,17.3 \mathrm{~Hz}$, $\mathrm{H}-10 \mathrm{e}), 2.33$ (3H, s, Me-18), 2.02 (3H, s, Me-16), 1.25 (6H, s, Me-13 and $\mathrm{Me}$ 14). ${ }^{13} \mathrm{C}-\mathrm{NMR}: 170.6$ (C-1), 86.0 (C-2), 38.5 (C-3), 126.6 (C-4), 131.7 (C-5), 117.9 (C-6), 151.9 (C-7), 116.8 (C-8), 129.6 (C-9), 28.1 (C-10), 70.9 (C-11) 75.1 (C-12), 24.8 (C-13), 22.6 (C-14), 169.6 (C-15), 21.1 (C-16), 168.7 (C-17), 21.0 (C-18), 169.1 (C-1'), 138.8 (C-2'), 124.4 (C-3'), 127.2 (C-4'), 128.9 (C-5' and C-9'), 122.2 (C-6' and C-8'), 151.0 (C-7'); EIMS m/z (rel. int.): $542[\mathrm{M}]^{+}$ (1), 525 (9), 524 (5), 465 (28), 405 (18), 412 (11), 352 (12), 313 (21), 261 (10), $231(28), 256(30), 216(10), 173(35), 99(12), 88(2)$;

\section{Biological activity}

\section{Antibacterial assay:}

The antibacterial activity was determined in solid media by the paper disc diffusion method ${ }^{14}$. The MIQ was measured as the minimal quantity that showed a transparent halo of growth inhibition. Five phytopathogen bacterial strains were used in the bioassay: Pseudomonas syringae pv syringae, Xanthomonas arboricola pv juglandis 833, Erwinia carotovora, Agrobacterium tumefaciens A348 (Gram-negative bacterias) and Clavibacter michiganensis 807 (Grampositive bacteria). Benzylpenicillin potassium salt (Sigma-Aldrich) and streptomycin sulfate (Calbiochem) were used as positive antibiotics.

\section{Antitumor assay:}

Antitumor activity of compounds was assessed with the potato disc method described by McLaughlin and Rogers in $1998^{15}$. In brief, potato tubers were surface sterilized in $1 \% \mathrm{NaClO}$ for $20 \mathrm{~min}$. Potato discs $(5 \mathrm{~mm}$ thick) were made with cork borer and placed on $2 \%$ agar plates ( 5 discs per plate). To each potato disc was applied $0.05 \mathrm{~mL}$ of a solution containing $2 \mathrm{~mL}$ of a broth culture of $A$. tumefaciens ( $48 \mathrm{~h}$ culture in Lauria-Bertani broth medium), $1.5 \mathrm{~mL}$ of sterile water and $0.5 \mathrm{~mL}$ of the solution of the compound tested ( 8 $\mathrm{mg}$ of compound in $2 \mathrm{~mL}$ of dimethyl sulfoxide, DMSO). Control discs were prepared with DMSO. A minimum of three Petri dishes ( $\%$ discs/dish) $(n=15-$ 25 ) were used for each test compound and the control. After preparation, the Petri dishes were placed in an incubator at $27^{\circ} \mathrm{C}$ for 12-21 days. The crown galls on the potato tuber discs were observed by the naked eye. Numbers of tumors per disc were counted, and percent inhibition for each concentration was determined as $\%$ inhibition $=100$ - (average number of tumors of sample/ ditto for the control) $x 100$.

Functional (contraction/relaxation) studies in rat isolated thoracic aorta rings:

Endothelium-denuded vascular rings were prepared from aortae of male Wistar rats weighing 210-270 g, essentially as described elsewhere ${ }^{16}$ Contraction studies were performed following the general procedure previously reported ${ }^{17}$. In the present study, however, isometric contractions were recorded by means of force-displacement transducers (Dynamometer UF1, Pioden Controls Ltd.,) connected to a MacLab ${ }^{\circledR}$ system (ADInstruments Pty Ltd,), controlled by a Power Macintosh 5500-225 computer.

After an equilibration period of at least $1 \mathrm{~h}$, isometric contractions induced by L-phenylephrine $(1 \mu \mathrm{M})$ were obtained. When contraction of the tissue in response to this vasoconstrictor agent had stabilized (after about 20 min), cumulatively increasing concentrations of the tested compounds (1-
$200 \mu \mathrm{M}$ ) were added to the bath at 5-10 min intervals (the time needed to obtain steady-state relaxation). Control tissues were subjected to the same procedures simultaneously, but omitting the compounds and adding the vehicle (appropriate dilutions of DMSO).

Contractile responses to phenylephrine are expressed as a percentage of the maximal contraction produced by this vasoconstrictor agent before the addition of the tested compounds. Sigmoidal concentration-response curves for the vasorelaxant effects of compounds were fitted using the program Origin $^{\mathrm{TM}} 7.0$ (Microcal Software, Inc., Northampton, USA), with estimation of $\mathrm{IC}_{50}$ values (i.e. concentrations inducing $50 \%$ relaxation) for phenylephrineinduced contractions.

Significant differences between two means $(p<0.05$ or $p<0.01)$ were determined by one-way analysis of variance (ANOVA) followed by the Dunnett's post-hoc test.

Appropriate dilutions of the above drugs were prepared every day immediately before use in deionized water from the following concentrated stock solutions kept at $-20^{\circ} \mathrm{C}$ : the tested compounds $(100 \mathrm{mM})$ in DMSO; L-phenylephrine $(100 \mathrm{mM})$ in deionized water. In our experiments, neither deionized water nor appropriate dilutions of the vehicle used had significant pharmacological effects.

\section{RESULTS AND DISCUSSION}

Chromatographic separation of compounds extracted from the culture of 2P-22 strain, Aspergillus sp. led to the isolation of 4 compounds 1-4: one new, $\mathbf{1}$, and three known compounds, named butyrolactone I, $\mathbf{2}^{11}$, and the two sesterterpenoids terretonin A, 3 and terretonin B, $\mathbf{4}^{8,9}$. The structures of the known compounds were confirmed by comparing their spectroscopic properties with those reported ${ }^{8-13}$.

Compound 1 was obtained as colourless crystals. Its molecular formula was established as $\mathrm{C}_{24} \mathrm{H}_{2} \mathrm{O}_{9}(\mathrm{~m} / z 458.0)$. The ${ }^{13} \mathrm{C}$ NMR and DEPT spectra of 1 showed 24 carbon signals for two methyl, one methoxy, two methylene, eight methines and 11 quaternary carbon atoms including two carbonyl carbons and a sp ${ }^{3}$ carbon bearing a hydroxyl group. The ${ }^{1} \mathrm{H}$ NMR spectra of $\mathbf{1}$ displayed signals for a 1,4-disubstituted phenolic moiety at $\delta 7.59(2 \mathrm{H}, \mathrm{d}, \mathrm{J}=8.8 \mathrm{~Hz})$ and $6.90(2 \mathrm{H}, \mathrm{d}, \mathrm{J}=8.8 \mathrm{~Hz})$, three aromatic proton signals of a 1,2,4-trisubstituted phenol $(\delta 6.58,6.55$ and $6.52 \mathrm{ppm})$, a signal at $\delta 3.78(3 \mathrm{H}, \mathrm{s}, \mathrm{OMe})$, a triplet at $\delta 3.76(\mathrm{~J}=4.9 \mathrm{~Hz})$ corresponding to a hydrogen geminal to a hydroxyl group, a pair of doublets at $\delta 3.53$ and $3.45(1 \mathrm{H}$ each, $\mathrm{d}, \mathrm{J}=14.7 \mathrm{~Hz})$ corresponding to the methylene connecting the butyrolactone with the trisubstituted aromatic ring, two double doublets at $\delta 2.88(1 \mathrm{H}, \mathrm{dd}, \mathrm{J}=4.7,17.0 \mathrm{~Hz})$ and $2.62(1 \mathrm{H}$, dd, J=5.03, 17.0 Hz), and two methyl groups at 1.31 and $1.24 \mathrm{ppm}$ ( See Experimental). The ${ }^{1} \mathrm{H}-\mathrm{NMR}$ data of compound 1 closely resembled those of butyrolactone I, $\mathbf{2}$ (Figure 1), with the only difference being the chemical shift of the prenyl residue, ie. the absence of a double bond in $\mathbf{2}$ and the appearance of a triplet at $\delta 3.76$ in $\mathbf{1}$ corresponding to a hydrogen geminal to a hydroxyl group.

In order to verify this structure, compound $\mathbf{1}$ was treated with acetic anhydride in pyridine affording compound $\mathbf{1 a}$. The comparison of the ${ }^{1} \mathrm{H}-\mathrm{NMR}$ spectra of compounds $\mathbf{1}$ and $\mathbf{1 a}$ showed only minor differences. The signal at $\delta$ 3.76 was shifted to $4.94 \mathrm{ppm}$ in $\mathbf{1} \mathbf{a}$, which suggested that the hydroxyl group at C-11 was acetylated, and the protons of 1,4-disubstituted phenol where shifted from $\delta 7.59$ and $6.90 \mathrm{ppm}$ in 1 to 7.72 and $7.20 \mathrm{ppm}$, indicating the acetylation of the 1,4 disubstituted phenol.

The structure of 1a (Figure 1) was determined based on the ${ }^{1} \mathrm{H}-{ }^{13} \mathrm{C}$ longrange correlations of the phenyl proton at $\delta 7.72\left(\mathrm{H}-5^{\prime}\right.$ ' and $\left.\mathrm{H}-9^{\prime} ; \delta_{\mathrm{C}} 128.9\right)$ with the carbons at $\delta 122.2$ (C-6' and C-8') and $151.0 \mathrm{ppm}\left(\mathrm{C}-7^{\prime}\right)$, and the phenyl protons at $\delta 7.20\left(\mathrm{H}-6^{\prime}\right.$ and $\left.\mathrm{H}-8^{\prime}\right)$ with the carbons at $\delta 128.9$ (C-5' and $\left.\mathrm{C}^{\prime} 9^{\prime}\right)$ and 151.0 (C-7'); the correlations between the multiplet at $\delta 6.62$ (corresponding to the phenyl protons $\mathrm{H}-8, \delta, 116.8$ and $\mathrm{H}-9, \delta$ 129.6) with carbons at $\delta 38.5(\mathrm{C}-3), 151.9(\mathrm{C}-7)$ and $131.7(\mathrm{C}-5)$; the ${ }^{1} \mathrm{H}-{ }^{13} \mathrm{C}$ long-range correlations of the methyl protons at $\delta 1.25(\mathrm{H}-13$ and $\mathrm{H}-14)$ with the carbons at $\delta 70.9(\mathrm{C}-11)$ and $75.1(\mathrm{C}-12)$. The protons at $\delta 3.56$ and $3.44(\mathrm{H}-3)$ showed long-range correlations with the carbons at $\delta 170.6(\mathrm{C}-1), 86.0(\mathrm{C}-2), 126.6$ (C-4), 131.7 (C-5) and 129.6 (C-9) indicating that this carbon is the linkage between the butyrolactone and the trisubstituted aromatic ring. The pair of double doublets at $\delta 2.90$ and 2.60 showed ${ }^{1} \mathrm{H}-{ }^{13} \mathrm{C}$ long-range correlations with $\delta 70.9$ (C-11), 75.0 (C-12), 117.9 (C-6), 131.7 (C-5) and 151.9 (C-7) indicating that the chain was linked to $\mathrm{C}-6$.

The assignments of the quaternary carbons were determined based on the comparison with butyrolactone I $\underline{\mathbf{2}} .^{11}$ Thus, the structure of compound $\mathbf{1}$ was elucidated as butyrolactone-VI. (Figure 1) 


\section{Biological activity}

The result of the antibacterial activity assay shows that $\underline{\mathbf{1}}$ and $\underline{\mathbf{2}}$ were only active against Clavibacter michiganensis. The MIQ value of butyrolactone VI (1) was $50 \mu \mathrm{g}$. The crown gall tumor bioassay used to test the compounds for antitumor activity was performed essentially according to McLaughlin \& Rogers ${ }^{15}$. It has been demonstrated that the compounds which inhibit these plant tumors have a high predictability of showing activity against the P288 (3PS) leukaemia in mice $^{18}$ and, in general, of disrupting the cell cycle (mitosis, $\mathrm{S}$ phase, etc.) regardless of their mode of action ${ }^{19}$. Compounds $\underline{\mathbf{1}}$ and $\underline{\mathbf{2}}$ showed a similar and significant inhibition of the growth of crown gall tumors on potato discs. The values were: butyrolactone I $\underline{\mathbf{2}}(84,46 \%)$ and butyrolactone VI $\underline{\mathbf{1}}(71$, $64 \%$ ), which suggests in vivo antitumor activity for both compounds.

Butyrolactone I $\underline{\mathbf{2}}$ was acetylated as usual (Py/acetic anhydride) yielding compound $\underline{\mathbf{2}}$. The potential vasorelaxant effects of compounds $\underline{\mathbf{2}}$ and $\underline{\mathbf{2}} \mathbf{a}$ were evaluated on endothelium-denuded rat aortic rings precontracted with L-phenylephrine. ${ }^{16,17} \mathrm{~L}$-phenylephrine caused slow and sustained contraction of the rat isolated aortic rings without endothelium. The maximal tension $(\mathrm{mg})$ reached was $2053.9 \pm 89(\mathrm{n}=5)$. These contractile effects were maintained without significant tension changes in control rings for at least $90 \mathrm{~min}$. DMSO had no significant effects on phenylephrine-induced contractions in endothelium-denudes rat aortic rings $(n=5, p>0.05)$. The cumulative addition of the tested compounds $(20-200 \mu \mathrm{M})$ concentration-dependently relaxed the contractions induced by L-phenylephrine (Figure 2). The butyrolactone I acetate was slightly less efficient than butyrolactone I in relaxing these contractions. However, the corresponding $\mathrm{IC}_{50}$ values of both compounds did not present significant differences (Table 1).

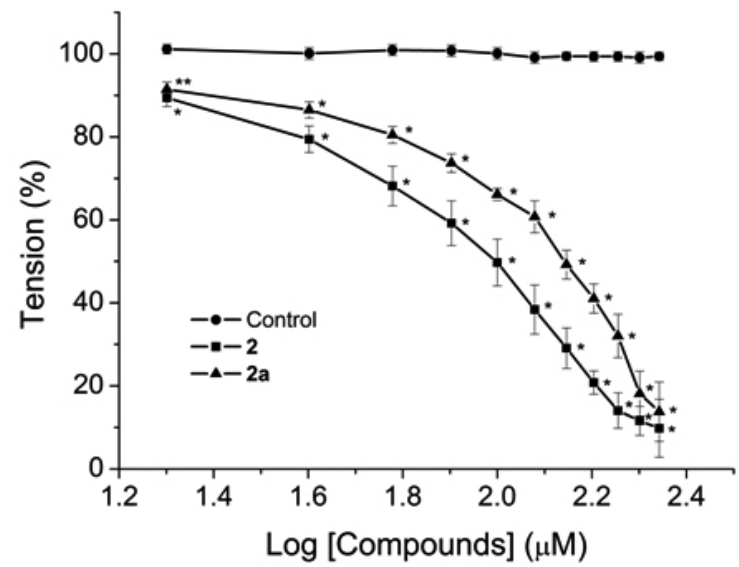

Figure 2. (a). Cumulative concentration-relaxation curves for the tested compounds $(20-200 \mu \mathrm{M})$ in endothelium-denuded rat thoracic aortic rings pre-contracted with phenylephrine $(1 \mu \mathrm{M})$. (b) Each point represents the mean value \pm s.e.m. (indicated by vertical lines) from 5 experiments. (c) Level of statistical significance: ${ }^{*} p<0.01 \mathrm{o} * * p<0.05$ with respect to the maximal tension $(100 \%)$, as determined by ANOVA/Dunnett's.

Table 1..- $\mathrm{IC}_{50}$ values $(\mu \mathrm{M})$ for the vasorelaxation induced by the tested compounds in endothelium-denuded rat aortic rings pre-contracted with L-phenylephrine.

\begin{tabular}{|c|c|}
\hline Compound & IC $_{\mathbf{5 0}}(\mu \mathbf{M})$ \\
\hline $\mathbf{2}$ & $91.6 \pm 7.1(\mathrm{n}=6)$ \\
\hline $\mathbf{2 a}$ & $121.7 \pm 9.8(\mathrm{n}=5)$ \\
\hline
\end{tabular}
ets.

Each value represents the mean \pm s.e.m from experiments shown in brack-

\section{CONCLUSIONS}

In summary, a new cytotoxic compound, butyrolactone VI, $\underline{\mathbf{1}}$, has been isolated from a strain of Aspergillus sp, isolated from a Chilean sponge Cliona chilensis. Its structure resembles that of other butyrolactones, previously characterized from marine strain of Aspergillus terreus and Aspergillus sp. ${ }^{10-13}$. These compounds were tested for antibacterial and antitumor assays and for potential vasorelaxant effects obtaining good responses suggesting that further studies to assess the potential of this type of structure are merited.

\section{ACKNOWLEDGEMENTS}

Financial support by a Grant Proyecto PBCT, PDA - 13 (Chile), Proyecto Anillo ACT-38, (CHILE) and CSIC-UCHILE Proyecto (02/2007-2008).

This article is dedicated to the memory of Prof. Francisco Orallo, who died in December 2009.

\section{REFERENCES}

1. Abdel-Wahab, M. A.; Asolkar, R. N.; Inderbitzin, P.; Fenical, W.; "Secondary metabolite chemistry of the marine-derived fungus Massarina sp., strain CNT-016" Phytochemistry, 68, 1212, (2007).

2. Bugni, T. S.; Ireland, C. M.; "Marine-derived fungi: a chemically and biologically diverse group of microorganisms". Nat. Prod. Rep., 21, 143163, (2004).

3. Faulkner, D. J.; "Marine Natural products" Nat Prod Rep., 18, 1, (2001).

4. Isaka, M.; Suyarnsestakorn, C.; Tanticharoen, M.; Kongsaeree, P.; Thebtaranonth, Y.; "Aigialomycins A-E, New Resorcylic Macrolides from the Marine Mangrove Fungus Aigialus parvus" J. Org. Chem., 67, 1561,(2002).

5. Abdel-Lateff, A.; Klemke, C.; König, G. M.; Wright, A. D.; "Two New Xanthone Derivatives from the Algicolous Marine Fungus Wardomyces anomalus" J. Nat. Prod., 66, 706, (2003).

6. Ciavatta, M. L.; Lopez-Gresa, M. P.; Gavagnin, M.; Nicoletti, R.; Manzo, E.; Mollo, E.; Guo, Y. W.; Cimino, G.; "Cytosporin-related compounds from the marine-derived fungus Eutypella scoparia" Tetrahedron, 64, 5365, (2008).

7. Bringmann, G.; Lang, G.; Steffens, S.; Schaumann, K.; "New Bioactive Compounds from Marine Organisms" J. Nat. Prod., 67, 311, (2004).

8. Springer, J. P.; Dorner, J. W.; Cole, R. J.; Cox, R. H.; "Terretonin, a Toxic Compound from Aspergillus terreus" J. Org. Chem., 44, 4852, (1979).

9. Li, G. Y.; Li, B. G.; Yang, T.; Yin, J. H.; Qi, H. Y.; Liu, G. Y.; Zhang, G. L.; "Sesterpenoids, Terretonins A - D, and an Alkaloid, Asterrelenin, from Aspergillus terreus

10. Lopez-Gresa, M.P., Cabedo,N., Gónzalez-Mas, M.C., Ciavatta,M.L., Avila, C. And Primo,J. "Terretonins E and F, Inhibitors of the Mitochondrial Respiratory Chain from the Marine-Derived Fungus Aspergillus insuetus ${ }^{\#}$, J. Nat. Prod., 72, 348, (2009).

11. Rao, K. V.; Sadhukhan, A. K.; Veerender, M.; Ravikumar, V.; Mohan, E. V. S.; Dhanvantri, S. D.; Sitaramkumar, M.; Moses Babu, J.; Vyas, K.; Om Reddy,G.; "Butyrolactones from the Fungus Aspergillus terreus BCC 4651"Chem. Pharm. Bull., 48, 559, (2000).

12. Kiriyama, N.; Nitta, K.; Sakaguchi,Y.; Taguchi,Y.; Yamamoto,Y.; "Butyrolactone I Derivatives from Aspergillus terreus Carrying an Unusual Sulfate Moiety" Chem. Pharm. Bull., 25, 2593, (1977).

13. Ting, L.; Chunhua, L.; Yuemao, S.; "Secondary metabolites of Aspergillus sp. F1, a commensal fungal strain of Trewia nudiflora" Nat. Prod. Res., 23, 77, (2009).

14. Jorgensen, J. H.; Turnidge, J. D.; Washington, J. A.; Antibacterial susceptibility tests: dilution and disk diffusion methods. In: "Manual of Clinical Microbiology" $7^{\text {th }}$ Ed.; Murray, P. R.; Baron, E. J.; Pfaller, M. A.; Tenover, F. C.; Yolken, R. H., Eds.; American Society for Microbiology, 1999, pp 1526-1543.

15. McLaughlin, J. L.; Rogers, L. L.; "The use of biological assays to evaluate botanicals" Drug Information Journal, 32, 513, (1998).

16. Orallo, F.; Study of the in vivo and in vitro cardiovascular effects of a hydralazine-like vasodilator agent (HPS-10) in normotensive rats. $B r . J$. Pharmacol., 121, 1627, (1997).

17. Orallo, F.; Alvarez, E.; Camiña M.; Leiro J.M.; Gómez, E.; Fernández, P.; "The Possible Implication of trans-Resveratrol in the Cardioprotective Effects of Long-Term Moderate Wine Consumption "Mol. Pharmacol., 61, 294, (2002).

18. Ferrigni, N. R.; Putnam, J. E.; Anderson, B.; Jacobsen, L. B.; Nichols, D. E.; Moore, D. S.; McLaughlin, J. L.; Powell, R. G.; Smith Jr., C. R.; "Modification and evaluation of the potato disc assay and antitumor screening of euphorbiaceae seeds" J. Nat. Prod., 45, 679, (1982).

19. Coker, P. S.; Radecke, J.; Guy, C.; Camper, N. D.; "Potato disc tumor induction assay: a multiple mode of drug action assay". Phytomedicine, , 10, 13, (2003). 